\title{
The Moldflow Analysis of Thin Plastic Injection Compression Molding Yongcheng Huang ${ }^{\mathrm{a}}$, Bin Yang ${ }^{\mathrm{b} *}$ and Zhiyong $\mathrm{Li}^{\mathrm{c}}$ \\ Guang Dong Polytechnic College, Zhaoqing 526100, China)

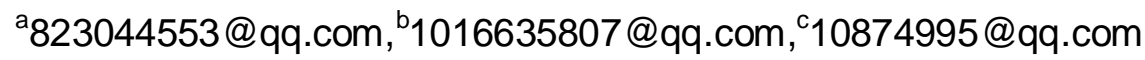

\begin{abstract}
Keywords: Injection compression; Minitab; Maximum warpage; Average weld line; Average volume shrinkage
\end{abstract}

\begin{abstract}
With the development of polymer materials, the application scope of injection molding products is becoming more and more extensive. This is becoming more and more demanding for the injection molding process, especially the products with high requirements for the thin wall, surface and strength of the injection molding, in addition to the requirements of its use, the traditional injection molding is difficult to be processed and complicated. Plastic parts. It is difficult to form high quality thin-walled plastic parts. Injection compression is a kind of precision injection molding. The process parameters affecting the quality of the plastic parts have many and mutual influence. The evaluation of the quality of the plastic parts should be judged from multiple targets. The advantages of injection-compression molding process on this paper. It can reduce the residual stress of the molding. So most of the optical plastic parts are produced by this method. In this paper, the Taguchi method of 5 levels and 6 factors was established on the basis of Minitab. Taking the shell of the computer display as the research object, the injection compression molding process under different technological conditions was simulated and analyzed. The maximum warpage deformation, the average weld line and the average volume contraction rate of three target values were analyzed respectively. Through the difference analysis, the influence degree of 6 process parameters, die temperature, melt temperature, compression force, compression speed, compression distance and compression time, is determined, and the corresponding trend diagram is drawn.
\end{abstract}

\section{Introduction}

The main forming method of plastic products is injection molding. There are more and more kinds of injection molding, and the requirements for the quality and accuracy of the products are getting higher and higher ${ }^{[1,2]}$. However, the traditional injection molding is designed and produced by the actual production experience of the designer, so the development cycle is very long, the efficiency is greatly reduced and the waste of production materials is easily caused, which will increase the production cost of. CAE technology provides a complete solution from product design to production and follow-up, greatly reducing product development cycle and reducing production costs. Injection molding is an advanced technology of injection molding combined with two forms of injection molding and compression molding. When the mold is not completely closed, it is injected into the melt, and then the melt is uniformly extruded under the compression force or even pressure to mold cavity. Injection molding technology has smaller clamping force and injection pressure than injection molding technology to reduce the internal stress of plastic parts. In the process of pressure protection, the force exerted is uniform, and then the deformation is reduced, which is conducive to improving the quality of thin-walled plastic parts ${ }^{[3]}$.

Because of the light weight and the longer flow length of the thin-walled plastic parts, the shrinkage is not uniform in the forming process, and it is easy to produce warping deformation. It is difficult to make the plastic parts with the thicker than that of the thick plastic parts. The traditional injection molding process makes the melt grease unevenly distributed and easily causes internal stress and warpage. The general injection molding process is to control the flow rate and pressure of the resin in the mold cavity indirectly by the motion of the precise control screw, and the injection compression molding can reduce the internal stress of the plastic parts and weaken the intermolecular orientation [1] because it can directly pressurize the resin through the cavity through the cavity. Therefore, the quality of the thin-walled plastic parts is raised. High. 


\section{Pre Processing of Injection Compression Molding Based on Moldflow}

The establishment of the model. Taking a brand laptop display case as an analysis model, its internal dimension $310 \mathrm{~mm} * 175 \mathrm{~mm}^{*} 1.5 \mathrm{~mm}$ and outer dimension $340 \mathrm{~mm}^{*} 230 \mathrm{~mm} * 1.5 \mathrm{~mm}$ belong to thin-wall plastic parts. The 3D model of the computer display shell is built in Pro/E, saved in IGS format, and then imported into Moldflow CAD Doctor to repair the defect. Finally, the repaired parts are introduced into the Moldflow software for simulation analysis. The 3D model, as shown in Figure 1, is based on the 3D grid division based on MOLDFLOW2018, the tetrahedral number is 57628 , the connected nodes are 10752 , the vertical and horizontal ratio is 28.26 , and the $3 \mathrm{D}$ grid is divided into ${ }^{[2]}$ in the permitted range, shown in Figure 2.

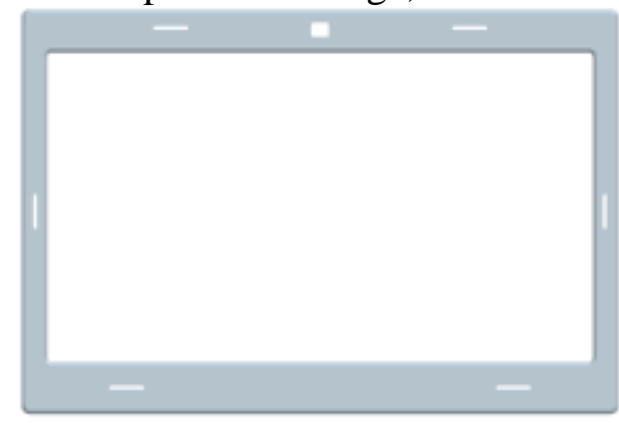

Figure 1 Display shell

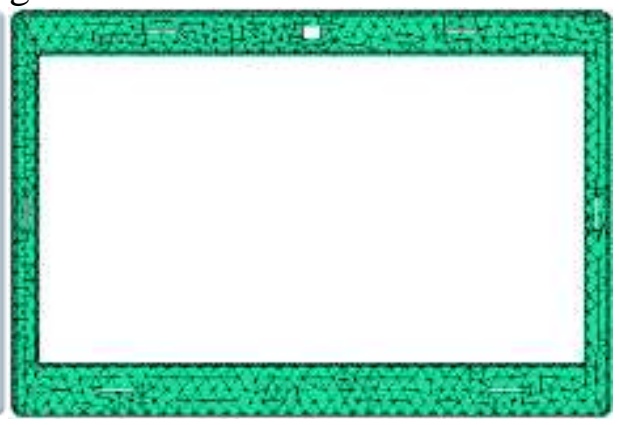

Figure 2 3D grid partition

Selection of materials. The shell of the notebook computer has the advantages of mechanical strength, heat dissipation, weight and gloss. The selection of engineering plastic PC+ABS has the advantages of thin wall, light weight, high strength, fast heat dissipation, good shielding and so on $^{[4,5]}$. Manufacturer Covestro, brand Baybtend FR3001 composite material used in this experiment.

Establishment of cooling system for gating system. The length of the computer display housing is larger than that of the computer display, and the quality of the single piece is only 64.3439 G. After analyzing the design of multi-point pouring, the productivity can be increased. The final determination of the four gate is suitable, the conical main channel is set, the diameter of the $6 \mathrm{~mm}$ small end, the large end diameter of $8 \mathrm{~mm}$, the main main channel length is $50 \mathrm{~mm}$, the branch channel is $6 \mathrm{~mm}$, the gate uses the latent gate, the diameter of the beginning is $1.2 \mathrm{~mm}$, the end diameter is $6 \mathrm{~mm}$, and the cooling pipe is $8 \mathrm{~mm}$ in the cold circuit. The distance between the water pipe and the parts is $15 \mathrm{~mm}$, the distance between the water pipes is $25 \mathrm{~mm}$, and the coolant is cooled by 50 degrees warm water for ${ }^{[6]}$. The whole system design is shown in Figure 3.

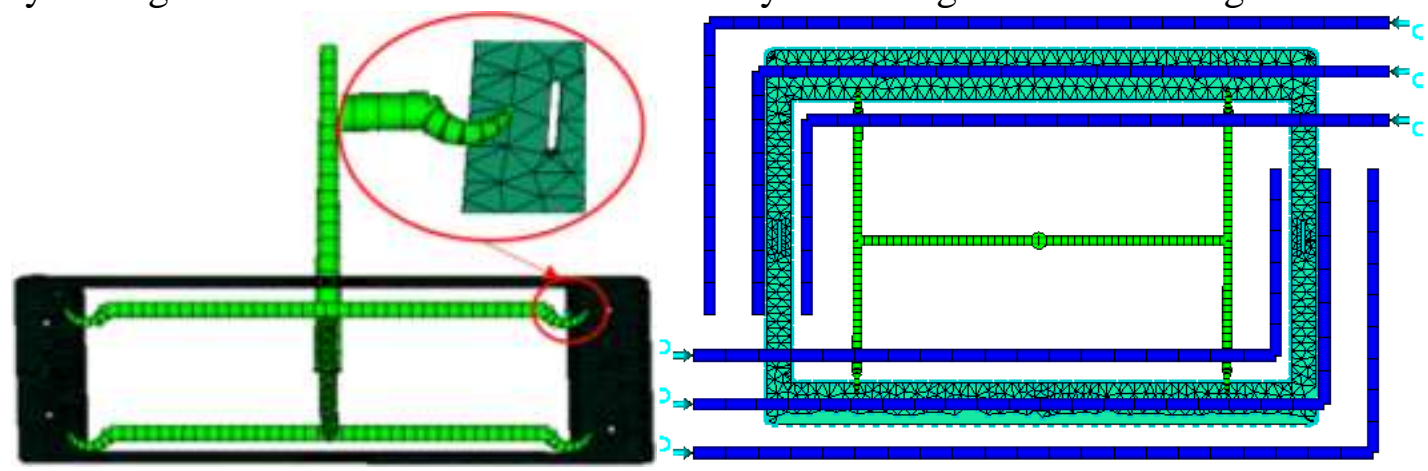

Figure 3 Casting system and cooling system

\section{Optimization Analysis of Injection Molding Process}

Establishment of multi index test scheme. The goal of this experiment is to find a better combination of process parameters to improve the comprehensive quality of injection products. The maximum warpage $(\mathrm{X} 1 / \mathrm{mm})$, average weld line $(\mathrm{X} 2 / \mathrm{deg})$ and average volumetric shrinkage $(\mathrm{X} 3 / \%)$ were selected as the main evaluation indexes. The smaller the $\mathrm{X} 1$ and the $\mathrm{X} 3$, the better, The bigger the $\mathrm{X} 2$, the better ${ }^{[3]}$. The level of specific parameters is shown in Table 1. 
Table 1 Factor level setting table

\begin{tabular}{|c|c|c|c|c|c|c|}
\hline \multirow{2}{*}{ level } & \multicolumn{7}{|c|}{ Process parameter factors } \\
\cline { 2 - 7 } & $\begin{array}{c}\text { Mould temp } \\
\left(\mathrm{A} /\left[{ }^{\circ} \mathrm{C}\right]\right)\end{array}$ & $\begin{array}{c}\text { Melt Tem } \\
\left(\mathrm{B} /\left[{ }^{\circ} \mathrm{C}\right]\right)\end{array}$ & $\begin{array}{c}\text { Com force } \\
(\mathrm{C} /[\text { tonne }])\end{array}$ & $\begin{array}{c}\text { Com speed } \\
\left(\mathrm{D} /\left[\mathrm{mms}^{-1}\right]\right)\end{array}$ & $\begin{array}{c}\text { Com distance } \\
(\mathrm{E} /[\mathrm{mm}])\end{array}$ & $\begin{array}{c}\text { Com time } \\
(\mathrm{F} /[\mathrm{s}])\end{array}$ \\
\hline 1 & 60 & 240 & 45 & 6 & 0.5 & 4 \\
\hline 2 & 65 & 250 & 50 & 8 & 1 & 7 \\
\hline 3 & 70 & 260 & 55 & 10 & 1.5 & 10 \\
\hline 4 & 75 & 270 & 60 & 12 & 2 & 13 \\
\hline 5 & 80 & 280 & 65 & 14 & 2.5 & 16 \\
\hline
\end{tabular}

Calculation and analysis of test results. Based on Minitab, a Taguchi experiment with 6 factors of 5 levels is established to generate an orthogonal matrix table, and the orthogonal table and simulation data are shown in Table 2.

Table 2 Taguchi method and test results

\begin{tabular}{|c|c|c|c|c|c|c|c|c|c|}
\hline \multirow{2}{*}{ Test number } & \multicolumn{7}{|c|}{ Factor parameter } & \multicolumn{3}{|c|}{ Test result } \\
\cline { 2 - 10 } & A & B & C & D & E & F & X1 & X2 & X3 \\
\hline 1 & 1 & 1 & 1 & 1 & 1 & 1 & 2.853 & 68.04 & 9.630 \\
\hline 2 & 1 & 2 & 2 & 2 & 2 & 2 & 1.504 & 67.88 & 11.39 \\
\hline 3 & 1 & 3 & 3 & 3 & 3 & 3 & 1.482 & 70.38 & 8.836 \\
\hline 4 & 1 & 4 & 4 & 4 & 4 & 4 & 1.997 & 69.22 & 9.079 \\
\hline 5 & 1 & 5 & 5 & 5 & 5 & 5 & 1.597 & 67.52 & 9.105 \\
\hline 6 & 2 & 1 & 2 & 3 & 4 & 5 & 2.842 & 73.39 & 9.909 \\
\hline 7 & 2 & 2 & 3 & 4 & 5 & 1 & 1.901 & 68.65 & 8.560 \\
\hline 8 & 2 & 3 & 4 & 5 & 1 & 2 & 1.135 & 69.27 & 8.86 \\
\hline 9 & 2 & 4 & 5 & 1 & 2 & 3 & 2.399 & 68.14 & 9.745 \\
\hline 10 & 2 & 5 & 1 & 2 & 3 & 4 & 1.209 & 69.26 & 9.968 \\
\hline 11 & 3 & 1 & 3 & 5 & 2 & 4 & 1.846 & 67.75 & 9.591 \\
\hline 12 & 3 & 2 & 4 & 1 & 3 & 5 & 1.098 & 69.8 & 8.570 \\
\hline 13 & 3 & 3 & 5 & 2 & 4 & 1 & 1.618 & 67.69 & 8.306 \\
\hline 14 & 3 & 4 & 1 & 3 & 5 & 2 & 1.311 & 69.32 & 9.562 \\
\hline 15 & 3 & 5 & 2 & 4 & 1 & 3 & 2.544 & 68.20 & 9.922 \\
\hline 16 & 4 & 1 & 4 & 2 & 5 & 3 & 1.299 & 68.49 & 9.789 \\
\hline 17 & 4 & 2 & 5 & 3 & 1 & 4 & 1.388 & 69.01 & 10.43 \\
\hline 18 & 4 & 3 & 1 & 4 & 2 & 5 & 1.233 & 69.38 & 9.175 \\
\hline 19 & 4 & 4 & 3 & 5 & 3 & 1 & 1.230 & 70.70 & 8.935 \\
\hline 20 & 4 & 5 & 2 & 1 & 4 & 2 & 1.290 & 68.01 & 9.747 \\
\hline 21 & 5 & 1 & 5 & 4 & 3 & 2 & 1.807 & 67.63 & 10.21 \\
\hline 22 & 5 & 2 & 1 & 5 & 4 & 3 & 1.258 & 69.14 & 9.333 \\
\hline 23 & 5 & 3 & 2 & 1 & 5 & 4 & 1.917 & 75.69 & 9.213 \\
\hline 24 & 5 & 4 & 3 & 2 & 1 & 5 & 1.849 & 67.73 & 9.119 \\
\hline 25 & 5 & 5 & 4 & 3 & 2 & 1 & 0.955 & 68.71 & 9.378 \\
\hline & & & & & & & & \\
\hline
\end{tabular}

Table 3 Calculation results of maximum warpage

\begin{tabular}{|c|c|c|c|c|c|c|}
\hline Level & $\mathrm{A}$ & $\mathrm{B}$ & $\mathrm{C}$ & $\mathrm{D}$ & $\mathrm{E}$ & $\mathrm{F}$ \\
\hline 1 & 1.8866 & 2.1294 & 1.5728 & 1.9114 & 1.9538 & 1.7114 \\
\hline 2 & 1.8972 & 1.4298 & 2.0194 & 1.4958 & 1.5874 & 1.1745 \\
\hline 3 & 1.6834 & 1.477 & 1.6616 & 1.5956 & 1.3652 & 1.7964 \\
\hline 4 & 1.288 & 1.7572 & 1.2968 & 1.801 & 1.801 & 1.6714 \\
\hline 5 & 1.5572 & 1.519 & 1.519 & 1.4132 & 1.605 & 1.7238 \\
\hline $\mathrm{R}$ & 0.6092 & 0.6996 & 0.7226 & 0.4982 & 0.5886 & 0.6219 \\
\hline Patch & 4 & 2 & 1 & 6 & 5 & 3 \\
\hline
\end{tabular}




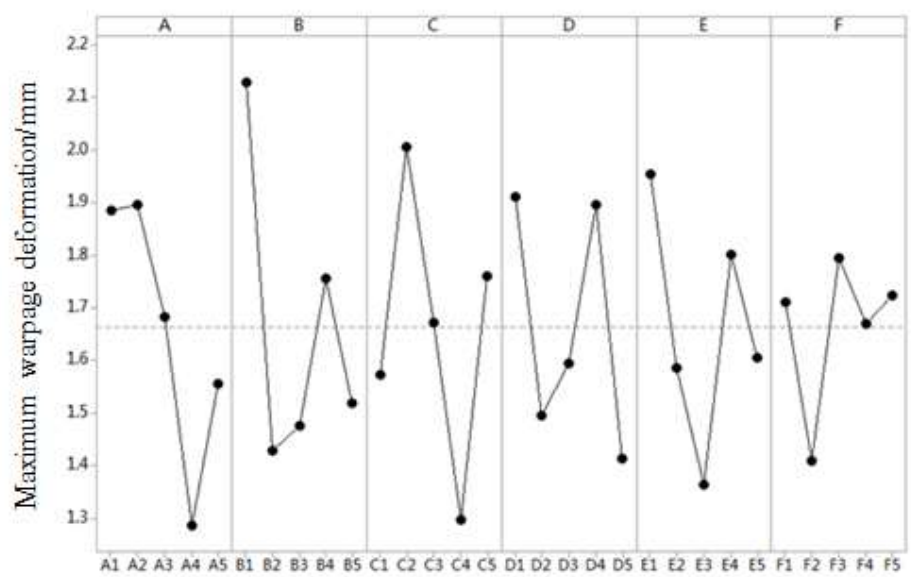

Figure 4. Trend map of maximum warpage

Table 3 and Figure 4 show that A, B, C, D, E, and F represent die temperature, melt temperature, compression force, compression speed, compression distance and compression time, and 1, 2, 3, 4, 5 are the level values of each factor. From the above chart, it is found that the factors that affect warpage are in turn $\mathrm{C}>\mathrm{B}>\mathrm{F}>\mathrm{A}>\mathrm{E}>\mathrm{D}$, the main factor affecting warpage is the compression force, the secondary factor is the melt temperature and the compression speed is the least. Increasing the die temperature and melt temperature can reduce warpage, and the best combination of technological parameters with the minimum warping deformation is A4B2C4D5E3F2.

Table 4 Calculation results of average melting connection pole difference

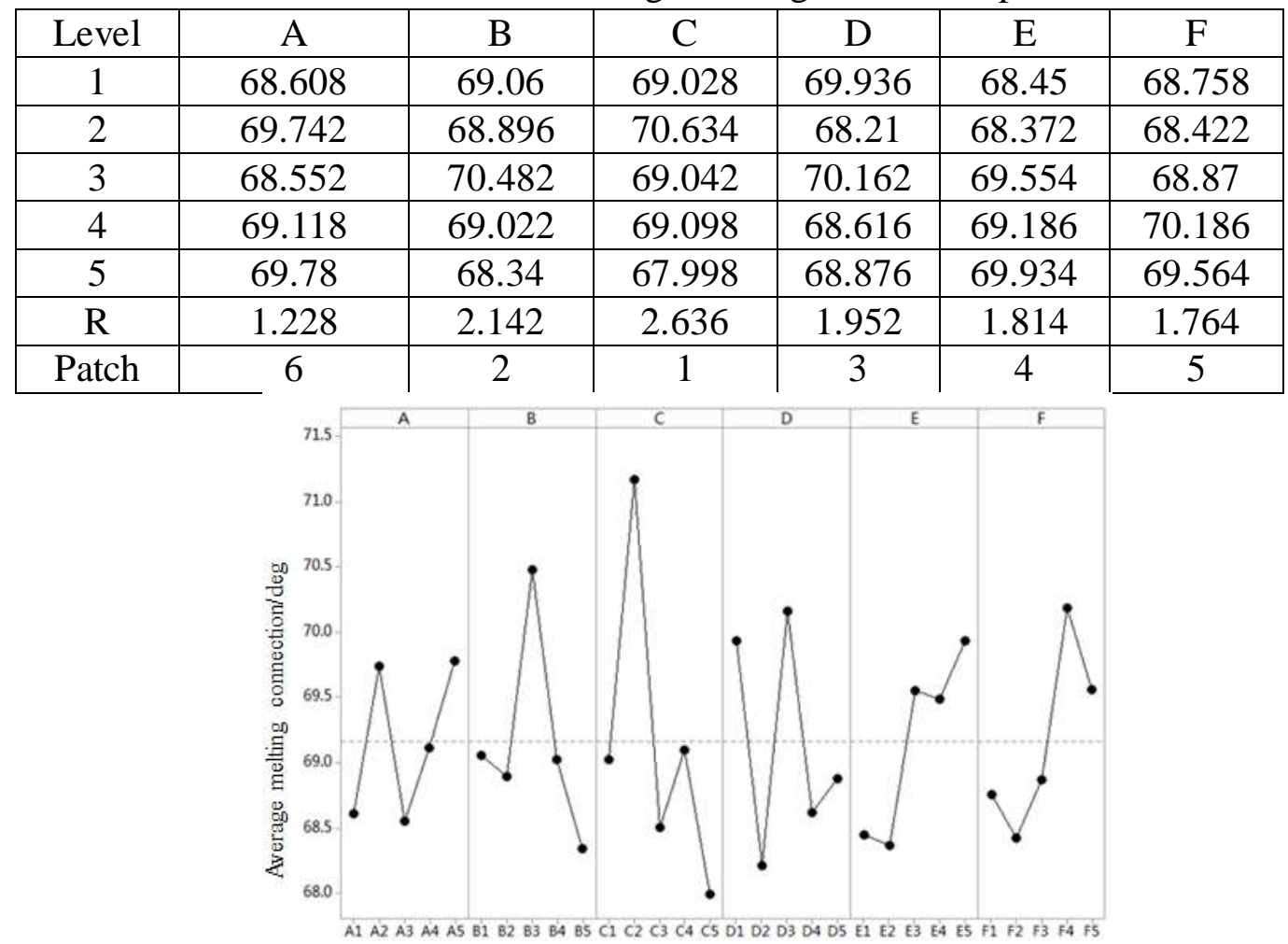

Figure 5. Melting connection trend diagram

The main factors affecting the weld line are compression force, followed by melt temperature and minimum die temperature in Table 4 and figure 5. Increasing the compression distance can increase the junction angle of the weld line. At the same time, it is confirmed that the faster the compression speed is, the quicker the weld line is, the faster the compression speed is, the greater the kinetic energy obtained by the moving material, the greater the impact force will be. The factors 
affecting the weld line are $\mathrm{C}>\mathrm{B}>\mathrm{D}>\mathrm{E}>\mathrm{F}>\mathrm{A}$ in sequence, and the best combination of technological parameters is $\mathrm{A} 5 \mathrm{~B} 3 \mathrm{C} 2 \mathrm{D} 3 \mathrm{E} 5 \mathrm{~F} 4$ when the weld line is maximum.

Table 5 Calculation results of average volume contraction rate

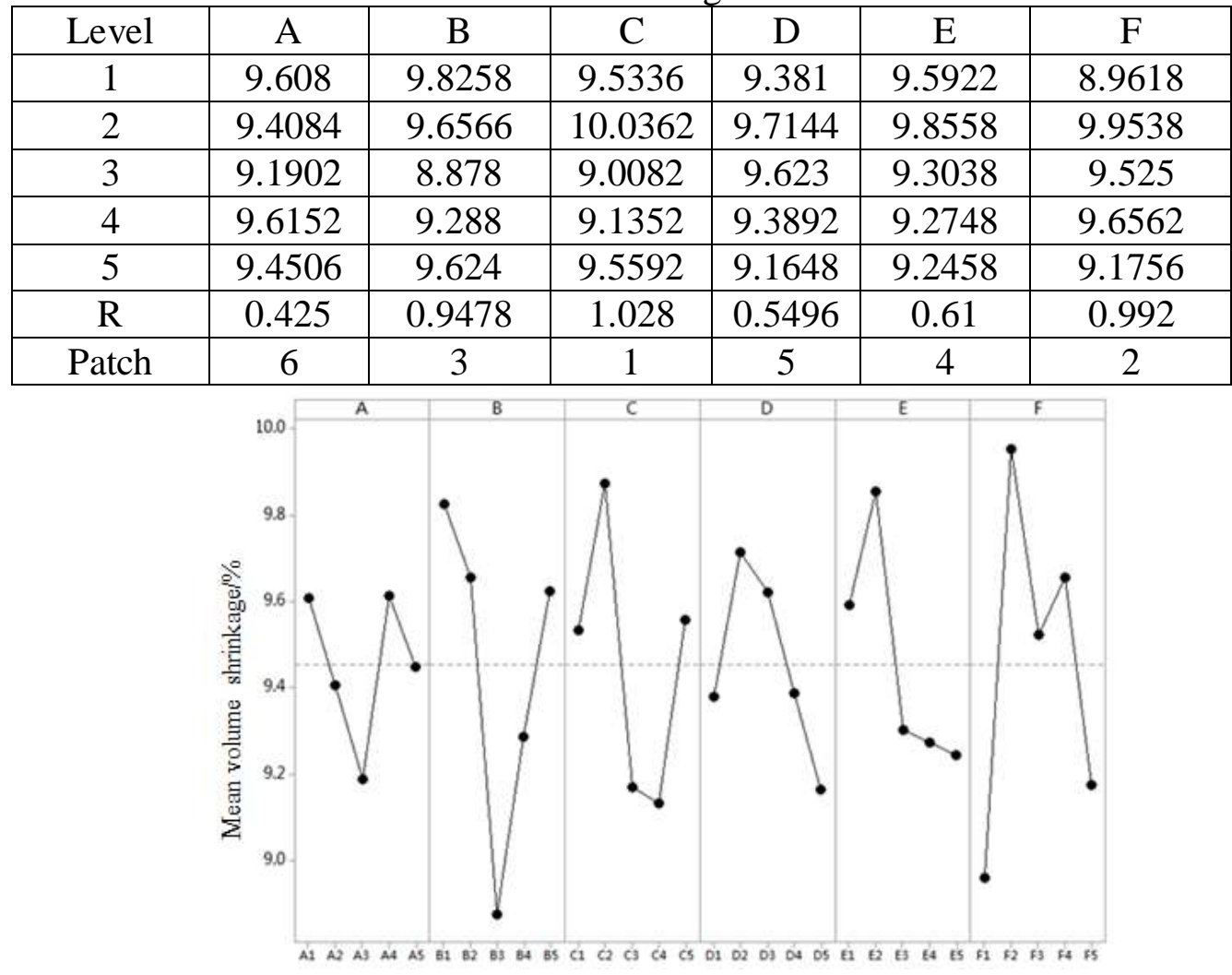

Figure 6. Trend map of average volume contraction rate

For the average volumetric shrinkage as shown in figures 6 and 5, the compression distance is the main factor, followed by the compression time. The factors affecting the average volumetric shrinkage rate are $\mathrm{C}>\mathrm{F}>\mathrm{B}>\mathrm{E}>\mathrm{D}>\mathrm{A}$ in turn, and the best combination of technological parameters with the average volume shrinkage rate is A3B3C4D5E5F1.

\section{Conclusion}

Based on Minitab, Taguchi method was used to establish a 6 factor 5 level orthogonal table, with 6 factors such as mould temp perature, melt temperature, compression force, compression speed, compression distance and compression time. The maximum warpage, the average melting connection and the average volume contraction rate were three evaluation indexes. The trend map of each index is obtained by the difference analysis. The trend map is used to deal with the experimental data in the future, and it has a certain guiding role to solve the multi-objective problem.

\section{Acknowledgements}

Guangdong Institute of Polytechnic innovation project in 2017(GKJ2017014), Guangdong Provincial Department of education, Guangdong Polytechnic, teaching team (171), Education and teaching reform fund of Guangdong province (2015770), Reform and research of PLC application technology course in Guangdong Polytechnic(JXGG2017033).

\section{Reference}

[1] Yin Xiao Yi. Study on Warpage control of injection molding for thin-walled plastic parts [D]. 
Chongqing, Chongqing Jiaotong University, 2017.

[2] Shen Honglei and other examples of Moldflow injection molding process tutorial [M]. Beijing: Electronics Industry Press, 2014.

[3] Huang Yongcheng. Aspheric lens injection compression molding process parameters optimization [D]. Kunming, Kunming University of Science and Technology, 2016.

[4] Li Meng et al. Effect of injection molding process on mechanical properties of long glass fiber reinforced polypropylene injection molding [J]. plastic industry, 2017 (08): 75-88.

[5] Sun Jianhua, Gu Hai, Zhang Jie. Analysis and optimization of warpage of thin-walled plastic parts based on CAE and DOE technology [J]. computer aided engineering, 2017 (03): 40-44.

[6] Huang Cheng, Huang Jianfeng and other.Moldflow2018 mold flow analysis from entry to master [M].Machinery Industry Press, 2018. 